\title{
Lipoprotein Lipase (LPL) Polymorphism and the Risk of Coronary Artery Disease: A Meta-Analysis
}

\author{
$\mathrm{Li} \mathrm{Xie}^{*,+}$ and You-Mei $\mathrm{Li}^{\dagger}$ \\ Department of Cardiovascular Medicine, Xinqiao Hospital, Third Military Medical University, \\ Chongqing 400037, China; ym_l10909@sohu.com \\ * Correspondence: xieli19871220@126.com \\ † These authors contributed equally to this study. \\ Academic Editor: Peter Clifton \\ Received: 19 November 2016; Accepted: 3 January 2017; Published: 16 January 2017
}

\begin{abstract}
Background: In recent years, the lipoprotein lipase (LPL) polymorphism has been extensively investigated as a potential risk factor for coronary artery disease (CAD). However, the results of these studies have been inconsistent. Therefore, we performed this meta-analysis to explore the association between LPL polymorphism and CAD risk. Methods: The literature was searched from electronic databases such as Embase, China Biological Medicine Database, PubMed, Knowledge Infrastructure, and China National Web of Science by the key words "coronary artery disease", "lipoprotein lipase" and "polymorphism". All of the studies included in this manuscript met the inclusion and exclusion criteria. An odds ratio (OR) analysis using a 95\% confidence interval (CI) was employed to assess the association of the LPL polymorphism with CAD susceptibility. Results: We performed a meta-analysis of 14 case-control studies including HindIII, Ser447X and PvuII polymorphism. A statistically significant increase in the risk of CAD was associated with LPL HindIII polymorphism. This included HindIII $\mathrm{H}^{+} \mathrm{H}^{+}$genotype $(\mathrm{OR}=1.28,95 \% \mathrm{CI}=1.09-1.49$, $\left.p=0.002, \mathrm{I}^{2}=43 \%\right)$ and $\mathrm{H}^{+}$allele genotype $\left(\mathrm{OR}=1.27,95 \% \mathrm{CI}=1.03-1.58, p=0.03, \mathrm{I}^{2}=67 \%\right)$. Ser447X XX genotype $\left(\mathrm{OR}=2.37,95 \% \mathrm{CI}=1.33-4.24, p=0.004, \mathrm{I}^{2}=53 \%\right)$ was also associated with CAD risk. However, PvuII polymorphism was found to have no significant association with CAD risk. Conclusions: LPL HindIII polymorphism was significantly associated with the risk of CAD. For Ser447X polymorphism, it was found that only XX genotype was significantly associated with CAD risk. Furthermore, PvuII polymorphism had no significant association with CAD risk. It was considered that LPL HindIII polymorphism might serve as a potential biomarker for CAD risk.
\end{abstract}

Keywords: coronary artery disease; lipoprotein lipase; polymorphism; meta-analysis

\section{Introduction}

Coronary artery disease (CAD) is one of the greatest causes of morbidity and mortality throughout the world. It accounts for roughly one-half of all cardiovascular deaths [1,2]. Although tobacco use and lipid metabolism disorder are the classical risk factors for $C A D$, some studies have found that $C A D$ shows strong familial aggregation, and a gene variant is also a key risk marker for CAD patients $[3,4]$. For example, Bai et al. found that the monocyte chemoattractant protein-1 (MCP-1)-2518A>G polymorphism was associated with susceptibility to CAD, especially in Caucasians [5]. By contrast, Zhang et al. found that the COX-2-765G $>C$ (rs20417) polymorphism was protective against CAD [6]. Meanwhile, a few studies have reported that lipoprotein lipase (LPL) gene polymorphism may be associated with CAD risk.

LPL is a key enzyme for lipid metabolism. It can hydrolyze the triglycerides of chylomicrons and very-low-density lipoprotein (VLDL) to provide free fatty acids for oxidation and utilization in the heart and other tissues, as well as for storage in adipose tissue $[7,8]$. The abnormal expression of 
LPL is part of some pathophysiological processes, such as diabetes, chylomicronemia, obesity, and atherosclerosis [9]. The LPL gene is located on chromosome 8p22. Over 100 mutations have been found in this gene [10,11]. A few studies have reported that the polymorphisms of HindIII, Ser447X and PvuII were associated with the risk of CAD [10,12-14]. However, these results were also controversial [14-17]. Some studies found no association between these gene variants of LPL and the risk of CAD [14,15].

In this study, we performed the meta-analysis to explore these inconsistencies between LPL gene variants and the risk of CAD. The results confirmed that the LPL HindIII polymorphism is significantly associated with increased risk of CAD. This polymorphism might serve as a potential biomarker for CAD risk.

\section{Materials and Methods}

\subsection{Literature Sources and Search Strategies}

The literature included in this study was searched from electronic databases including Embase, China Biological Medicine Database, PubMed, Knowledge Infrastructure, and China National Web of Science. The key words were as follow: "coronary artery disease", "lipoprotein lipase" and "polymorphism". The relative of the references from the retrieved studies were also included. The last search was updated on 15 December 2015, with publication years ranging from 2000 to 2015.

\subsection{Inclusion and Exclusion Criteria}

The studies were selected based on the following inclusion criteria: the case-control studies discussed the polymorphism of LPL and the risk of CAD; the studies supplied the number of individual genotypes for the LPL polymorphisms in the CAD cases and controls; and the studies conform to the Hardy-Weinberg equilibrium (HWE). In addition, the following exclusion criteria were used: the study did not provide the detailed data that are typically presented in abstracts, meeting reports and reviews; the genotype frequency was not reported; and the studies repeated or overlapped other publications.

\subsection{Data Extraction}

The information was drawn out according to a standard protocol. Repeated publications were only adopted once and studies violating the inclusion criteria or providing insufficient data were excluded. The extracted data in Table 1 comprise the following items: the first author's name, publication date, region of study, ethnicity of the sample population, number of genotypes, total number of cases and controls and HWE. Two authors ( $\mathrm{Li}$ Xie and You-Mei Li) independently extracted the above information and disagreement was discussed by all authors to obtain consensus.

\subsection{Statistical Analyses}

Deviation from the Hardy-Weinberg equilibrium was examined by the Chi-square test. The odds ratio (OR) and the corresponding 95\% confidence interval (CI) between the case and control groups was used to assess the strength of the association between the LPL polymorphisms and the risk of CAD. For the HindIII, Ser447X and PvuII polymorphisms, we pooled the OR by comparing the risk allele carrier genotypes versus the wild-type genotype for low frequency of the homozygous variant. The statistical significance of the summary OR was determined by the $\mathrm{Z}$ test with the significance set as $p$ value less than 0.05 . If there was heterogeneity among the individual studies, the random effects model was adopted to calculate the overall OR value [18]. Otherwise, the fixed effects model was adopted [19]. To determine the publication bias, the funnel plot was used. The Egger's linear regression test on the natural logarithm scale of the OR was used to assess the funnel plot asymmetry; the significance was set at the $p<0.05$ level [20,21]. All statistical analyses were performed with RevMan V.5.0 software (Nordic Cochran Centre: Copenhagen, Denmark). 


\section{Results}

\subsection{Study Characteristics}

The databases of Embase, China Biological Medicine Database, PubMed, Knowledge Infrastructure, and China National Web of Science were used to identify literature for inclusion in this study. The following key words were entered: "coronary artery disease", "lipoprotein lipase" and "polymorphism". Originally, 224 potentially relevant studies were identified and screened. Then, these studies were carefully analyzed and 14 case-control studies were selected [13-17,22-30]. The detailed study selection process is illustrated in Figure 1. For the HindIII polymorphism and the risk of CAD, seven studies that involved 1853 cases and 1171 controls were available [13-15,22,25,28,30]. For the Ser447X polymorphism, eight studies that included 1519 cases and 824 controls were available [14,15,23-26,28,29]. For the PvuII polymorphism, six studies with 1064 cases and 832 controls were selected [14-17,25,27]. All of the studies included in the meta-analysis were consistent with HWE in the control populations. The detailed characteristics of the studies included in this meta-analysis are shown in Table 1. The distribution of HindIII, Ser447X and PvuII polymorphism genotype is listed in Table 2.

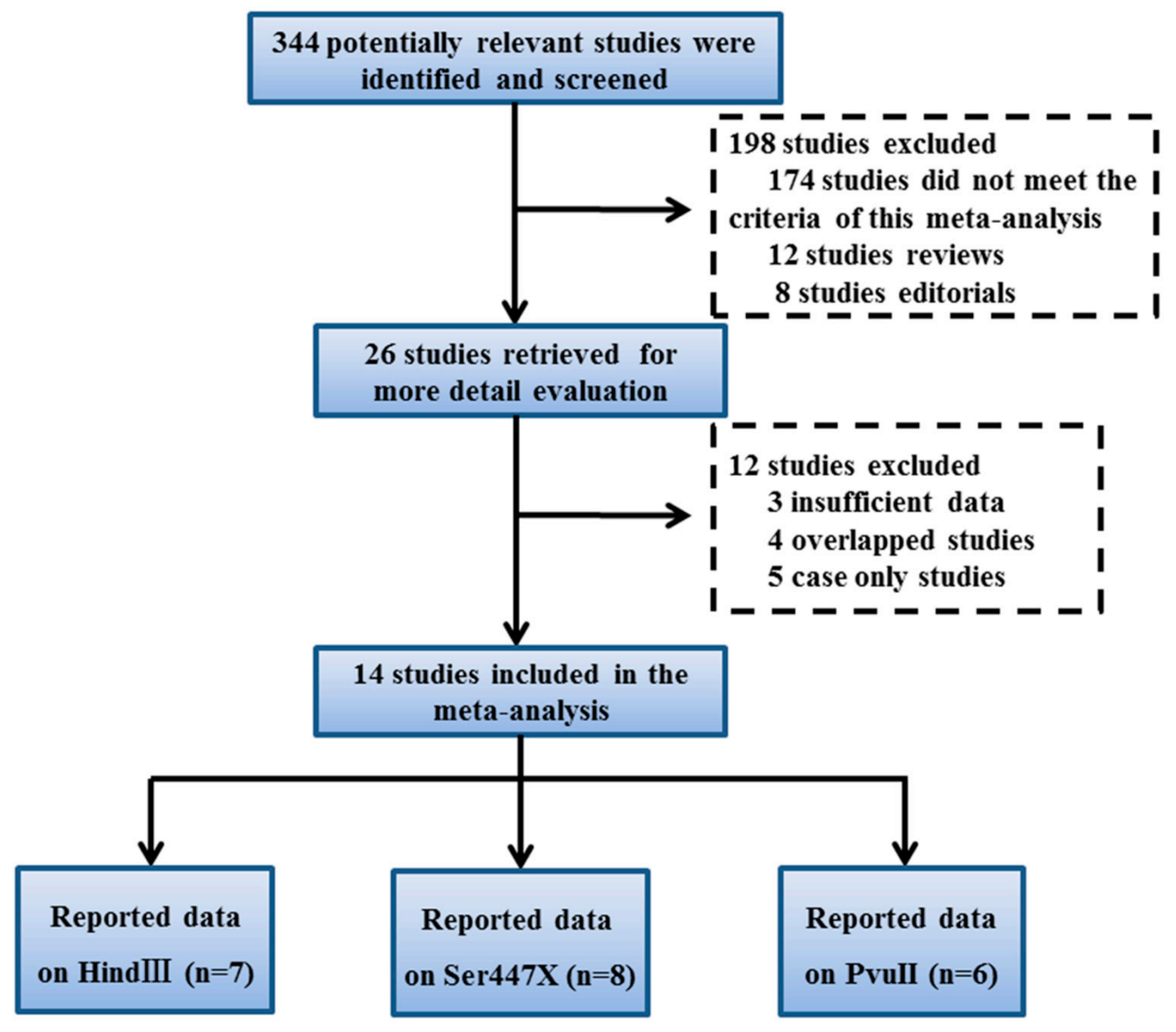

Figure 1. Flow of study identification, inclusion, and exclusion. 
Table 1. Characteristics of studies included in meta-analysis.

\begin{tabular}{|c|c|c|c|c|c|c|c|}
\hline Study & Years & Ethnicity & No. of Case/Control & Matching Criteria & Control Source & Genotyping & HWE \\
\hline \multicolumn{8}{|c|}{ HindIII Polymorphism } \\
\hline Abu-Amero [14] & 2003 & Saudi Arabian & $352 / 410$ & Sex, Age & HB & PCR & Yes \\
\hline Ahmadi [22] & 2015 & Iranian & $108 / 89$ & Sex, Age & $\mathrm{HB}$ & PCR & Yes \\
\hline Al-Jafari [15] & 2012 & Saudi Arabian & $120 / 65$ & Sex, Age & HB & PCR & Yes \\
\hline Daoud [25] & 2013 & Saudi Arabian & $226 / 103$ & Sex, Age & HB & PCR & Yes \\
\hline Pasalic [28] & 2006 & Croatian & $132 / 98$ & Sex, Age & $\mathrm{HB}$ & PCR & Yes \\
\hline Tanguturi [13] & 2013 & Indian & $202 / 210$ & Sex, Age & $\mathrm{HB}$ & PCR & Yes \\
\hline Whiting [30] & 2004 & American & $713 / 196$ & Sex, Age & $\mathrm{HB}$ & PCR & Yes \\
\hline \multicolumn{8}{|c|}{ PvuII Polymorphism } \\
\hline Abu-Amero [14] & 2003 & Saudi Arabian & $431 / 511$ & Sex, Age & HB & PCR & Yes \\
\hline Al-Jafari [15] & 2012 & Saudi Arabian & $120 / 65$ & Sex, Age & $\mathrm{HB}$ & PCR & Yes \\
\hline Daoud [25] & 2013 & Saudi Arabian & $226 / 103$ & Sex, Age & $\mathrm{HB}$ & PCR & Yes \\
\hline Duman [17] & 2004 & Turkish & $78 / 49$ & Sex, Age & $\mathrm{HB}$ & PCR & Yes \\
\hline Georgiev [16] & 2008 & Macedonian & $109 / 32$ & Sex, Age & $\mathrm{HB}$ & PCR & Yes \\
\hline Isbir [27] & 2003 & Turkish & $100 / 72$ & Sex, Age & HB & PCR & Yes \\
\hline \multicolumn{8}{|c|}{ Ser447X Polymorphism } \\
\hline Ahmadi [22] & 2015 & Iranian & $115 / 89$ & Sex, Age & $\mathrm{HB}$ & PCR & Yes \\
\hline Al-Jafari [15] & 2012 & Saudi Arabian & $120 / 65$ & Sex, Age & $\mathrm{HB}$ & PCR & Yes \\
\hline Almeida [23] & 2006 & Brazil & $313 / 150$ & Sex, Age & HB & PCR & Yes \\
\hline Aydogan [24] & 2009 & Turkey & $41 / 23$ & Sex, Age & $\mathrm{HB}$ & PCR & Yes \\
\hline Daoud [25] & 2013 & Saudi Arabian & $226 / 103$ & Sex, Age & $\mathrm{HB}$ & PCR & Yes \\
\hline Ferencak [26] & 2003 & Croatian & $479 / 200$ & Sex, Age & $\mathrm{HB}$ & PCR & Yes \\
\hline Pasalic [28] & 2006 & Croatian & $132 / 98$ & Sex, Age & $\mathrm{HB}$ & PCR & Yes \\
\hline Sawano [29] & 2001 & Japanese & $93 / 96$ & Sex, Age & $\mathrm{HB}$ & PCR & Yes \\
\hline
\end{tabular}

HB: hospital based, HWE: Hardy-Weinberg equilibrium. 
Table 2. Genotypes and allele frequencies of Lipoprotein Lipase (LPL) genes in patients and controls.

\begin{tabular}{|c|c|c|c|c|c|c|c|c|c|c|c|c|c|}
\hline \multirow{2}{*}{\multicolumn{2}{|c|}{$\begin{array}{cr}\text { Author } \quad \text { Year } \\
\text { HindIII Polymorphism }\end{array}$}} & \multicolumn{5}{|c|}{ Case } & \multicolumn{5}{|c|}{ Control } & \multirow[t]{2}{*}{ Sample Size } & \multirow[t]{2}{*}{ HWE (P) } \\
\hline & & $\mathbf{H}^{+} \mathbf{H}^{+}$ & $\mathbf{H}^{+} \mathbf{H}^{-}$ & $\mathbf{H}^{-} \mathbf{H}^{-}$ & $\mathbf{H}^{+}$ & $\mathbf{H}^{-}$ & $\mathbf{H}^{+} \mathbf{H}^{+}$ & $\mathbf{H}^{+} \mathbf{H}^{-}$ & $\mathbf{H}^{-} \mathbf{H}^{-}$ & $\mathbf{H}^{+}$ & $\mathbf{H}^{-}$ & & \\
\hline Abu-Amero [14] & 2003 & 189 & 138 & 25 & 516 & 188 & 206 & 173 & 31 & 585 & 235 & $352 / 410$ & Yes \\
\hline Pasalic [28] & 2006 & 78 & 46 & 8 & 202 & 62 & 47 & 45 & 6 & 139 & 57 & $132 / 98$ & Yes \\
\hline Whiting [30] & 2005 & 385 & 269 & 59 & 1039 & 387 & 103 & 77 & 16 & 283 & 109 & $713 / 196$ & Yes \\
\hline Daoud [25] & 2013 & 102 & 81 & 43 & 285 & 167 & 42 & 35 & 26 & 119 & 87 & $226 / 103$ & Yes \\
\hline Al-Jafari [15] & 2012 & 61 & 53 & 6 & 175 & 65 & 29 & 23 & 13 & 81 & 49 & $120 / 65$ & Yes \\
\hline Tanguturi [13] & 2013 & 98 & 72 & 32 & 268 & 136 & 70 & 68 & 72 & 208 & 212 & $202 / 210$ & Yes \\
\hline Ahmadi [22] & 2015 & 61 & 41 & 6 & 163 & 53 & 53 & 33 & 3 & 139 & 39 & $108 / 89$ & Yes \\
\hline \multicolumn{2}{|c|}{ Ser447X Polymorphism } & SS & SX & $X X$ & $\mathrm{~S}$ & $x$ & SS & SX & $\mathbf{X X}$ & $\mathrm{S}$ & $X$ & & \\
\hline Ahmadi [22] & 2015 & 58 & 23 & 34 & 139 & 91 & 75 & 7 & 7 & 157 & 21 & $115 / 89$ & Yes \\
\hline Al-Jafari [15] & 2012 & 100 & 20 & 0 & 220 & 20 & 57 & 8 & 0 & 122 & 8 & $120 / 65$ & Yes \\
\hline Almeida [23] & 2007 & 257 & 47 & 9 & 561 & 65 & 115 & 34 & 1 & 264 & 36 & $313 / 150$ & Yes \\
\hline Aydogan [24] & 2009 & 27 & 10 & 4 & 64 & 18 & 17 & 2 & 4 & 36 & 10 & $41 / 23$ & Yes \\
\hline Daoud [25] & 2013 & 185 & 41 & 0 & 411 & 41 & 92 & 11 & 0 & 195 & 11 & $226 / 103$ & Yes \\
\hline Ferencak [26] & 2003 & 378 & 97 & 4 & 853 & 105 & 167 & 32 & 1 & 366 & 34 & $479 / 200$ & Yes \\
\hline Pasalic [28] & 2006 & 113 & 19 & 0 & 245 & 19 & 69 & 28 & 1 & 166 & 30 & $132 / 98$ & Yes \\
\hline Sawano [29] & 2001 & 82 & 10 & 1 & 174 & 12 & 71 & 23 & 2 & 145 & 27 & $93 / 96$ & Yes \\
\hline \multicolumn{2}{|c|}{ PvuII Polymorphism } & $\mathbf{P}^{+} \mathbf{P}^{+}$ & $\mathbf{P}^{+} \mathbf{P}^{-}$ & $\mathbf{P}^{-} \mathbf{P}^{-}$ & $\mathbf{P}^{+}$ & $\mathbf{P}^{-}$ & $\mathbf{P}^{+} \mathbf{P}^{+}$ & $\mathbf{P}^{+} \mathbf{P}^{-}$ & $\mathbf{P}^{-} \mathbf{P}^{-}$ & $\mathbf{P}^{+}$ & $\mathbf{P}^{-}$ & & \\
\hline Abu-Amero [14] & 2003 & 138 & 225 & 68 & 501 & 361 & 182 & 248 & 81 & 612 & 410 & $431 / 511$ & Yes \\
\hline Al-Jafari [15] & 2012 & 50 & 52 & 18 & 152 & 88 & 25 & 28 & 12 & 78 & 52 & $120 / 65$ & Yes \\
\hline Daoud [25] & 2013 & 89 & 102 & 35 & 280 & 172 & 46 & 44 & 13 & 136 & 70 & $226 / 103$ & Yes \\
\hline Duman [17] & 2004 & 25 & 39 & 14 & 89 & 67 & 14 & 16 & 19 & 44 & 54 & $78 / 49$ & Yes \\
\hline Georgiev [16] & 2008 & 25 & 58 & 26 & 158 & 110 & 5 & 20 & 7 & 30 & 34 & $109 / 32$ & Yes \\
\hline Isbir [27] & 2003 & 37 & 49 & 14 & 123 & 77 & 20 & 40 & 12 & 80 & 64 & $100 / 72$ & Yes \\
\hline
\end{tabular}




\subsection{Association of the HindIII Polymorphism with CAD}

Data from seven studies that included 1853 cases and 1171 controls were pooled together for analysis of the association between the HindIII polymorphism and the risk of CAD. The overall data showed that individuals who carried the HindIII $\mathrm{H}^{+} \mathrm{H}^{+}$genotype had a significantly increased CAD risk compared with those who carried the HindIII $\mathrm{H}^{+} \mathrm{H}^{-}$and $\mathrm{H}^{-} \mathrm{H}^{-}$genotypes in all subjects $\left(\mathrm{OR}=1.28,95 \% \mathrm{CI}=1.09-1.49, p=0.002, \mathrm{I}^{2}=43 \%\right.$, Figure 2$)$. Because the heterogeneity among the studies was not significant (all $p>0.05$ ), the fixed-effects model was conducted. In addition, we found that the $\mathrm{H}^{+}$allele genotype was significantly associated with increased CAD risk when compared with the $\mathrm{H}^{-}$allele genotype $\left(\mathrm{OR}=1.27,95 \% \mathrm{CI}=1.03-1.58, p=0.03, \mathrm{I}^{2}=67 \%\right.$, Figure 3 ). It was also determined that the heterozygous and recessive genetic models had no association with the risk of CAD.

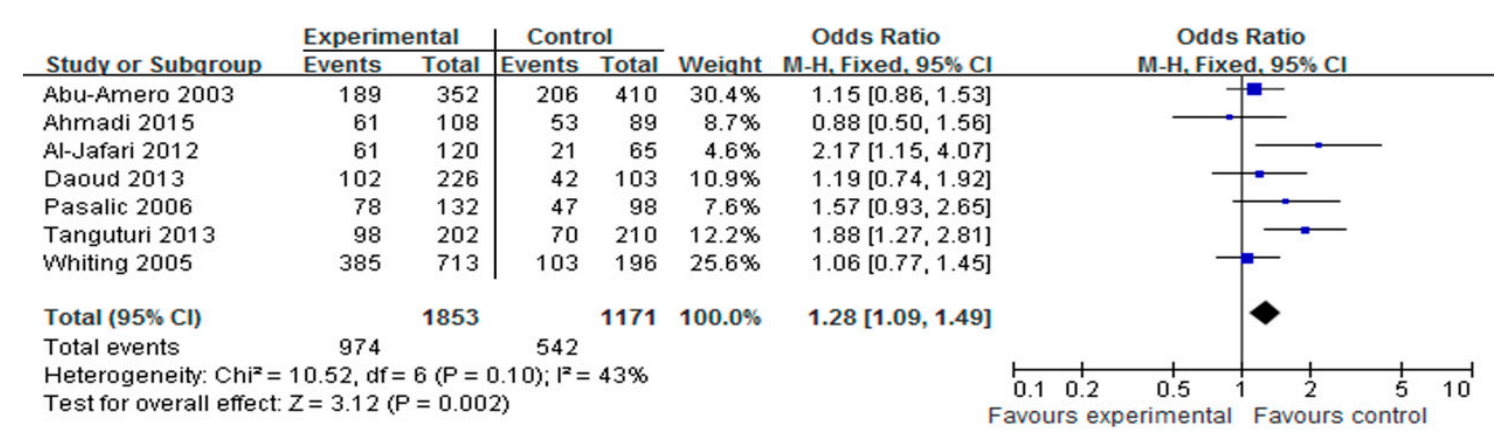

Figure 2. Forest plot of HindIII $\mathrm{H}^{+} \mathrm{H}^{+}$genotype associated with CAD risk.

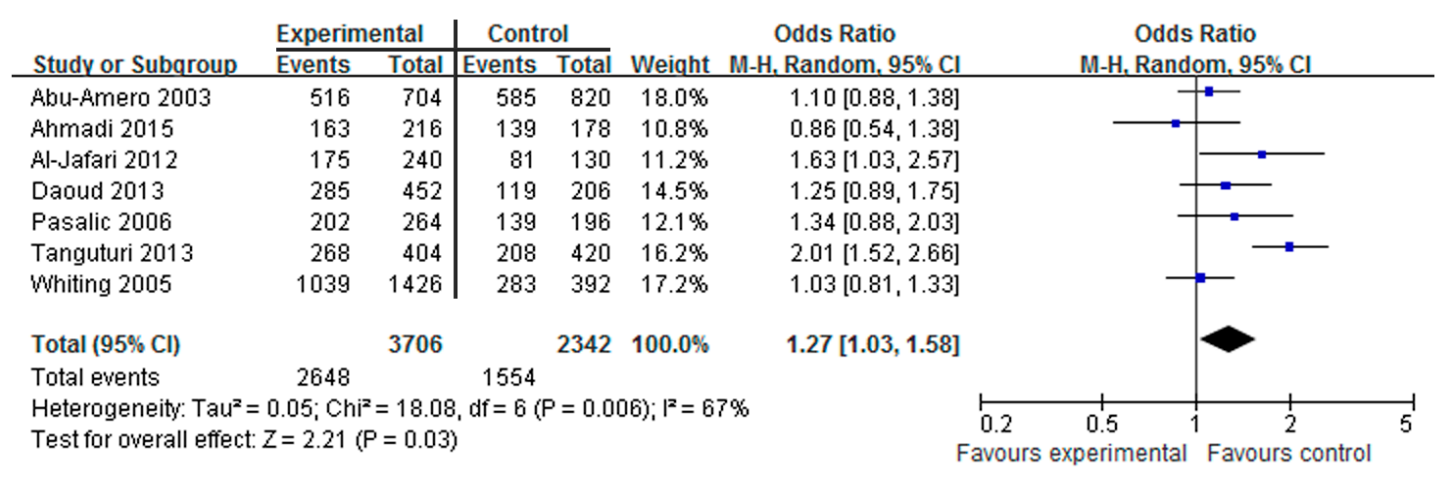

Figure 3. Forest plot of HindIII $\mathrm{H}^{+}$allele genotype associated with CAD risk.

\subsection{Association of the Ser447X Polymorphism with CAD}

Eight studies examining CAD were included for the evaluation of the association with the LPL Ser447X polymorphism. As the heterogeneity was not significant $(p=0.06)$, the fixed-effects model was used. It was determined that the individuals who carried the Ser447X XX genotype had a significantly increased CAD risk compared with those who carried the Ser447X other genotypes in all subjects $\left(\mathrm{OR}=2.37,95 \% \mathrm{CI}=1.33-4.24, p=0.004, \mathrm{I}^{2}=53 \%\right.$, Figure 4$)$. In the $\mathrm{X}$ allele genetic model, the heterogeneity was significant $(p<0.0001)$, and the random-effects model was used for analysis. It was found that $X$ allele genetic model had no significant association with CAD risk $(\mathrm{OR}=1.04$, $\left.95 \% \mathrm{CI}=0.60-1.80, p=0.90, \mathrm{I}^{2}=87 \%\right)$. In addition, we analyzed other genetic models and found that the heterozygous and dominant genetic models had no association with the risk of CAD. 


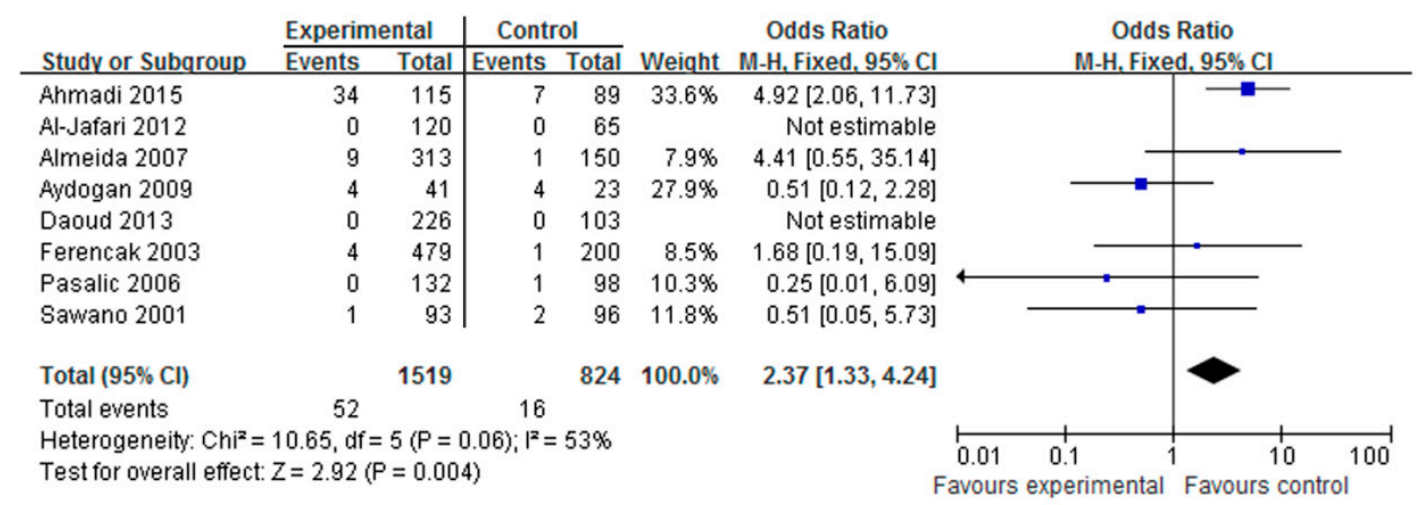

Figure 4. Forest plot of Ser447X XX genotype associated with CAD risk.

\subsection{Association of the PvuII Polymorphism with CAD}

Data from six studies that included 1064 cases and 832 controls were pooled together to analyze the association between the Pvull polymorphism and the risk of CAD. For the dominant genetic model, the fixed-effects model was conducted because the heterogeneity was not significant $(p=0.45)$. It was determined that this genetic model had no significant association with the risk of CAD (OR $=0.96$, $95 \% \mathrm{CI}=0.79-1.17, p=0.68, \mathrm{I}^{2}=0 \%$ ). It was also determined that the allele genetic model and the heterozygous and recessive genetic models had no associations with the risk of CAD.

\subsection{Sensitivity Analyses and Publication Bias}

A single study included in the meta-analysis was excluded following sequential omission. The corresponding pooled ORs were not materially altered in any subjects with either the HindIII or PvuII genotypes, suggesting the stability of the meta-analysis (data not shown). To assess the publication bias of the meta-analysis, Begg's funnel plot and Egger's test were performed. The funnel plot shapes were symmetrical for all the polymorphisms of HindIII and PvuII genotypes (data not shown). The statistical results did not suggest any evidence of publication bias among these studies. However, for Ser447X genotype, it was found that when the study by Ahmadi and colleagues was deleted, the sensitivity analysis was unstable and publication bias existed [22]. Therefore, it was considered that the association between Ser447X polymorphism and CAD risk still requires further research.

\section{Discussion}

In this study, we first performed a meta-analysis for the association between LPL polymorphism and CAD risk. It was found that the LPL HindIII polymorphism was positively correlated with CAD risk. In contrast, the LPL PvuII polymorphism had no association with CAD risk. Further research on the association between LPL Ser447X polymorphism and CAD risk is still needed.

The LPL gene spans over $30 \mathrm{~kb}$, comprising 10 exons and nine introns on chromosome 8p22. Its cDNA is translated to a 475 amino acid proteins, including a 27 amino acid signal peptide. Several sequence variations, including BamHI, PvuII, HindIII, BstNI and Ser447X sites, have been identified by restriction fragment length polymorphisms (RFLPs) in the LPL gene [31-33]. Among these variations, the HindIII, Ser447X and PvuII polymorphisms were the most common and may be associated with profound alterations in plasma lipids. Recently, some studies have reported that the HindIII, Ser447X and PvuII gene plolymorphisms decreased plasma LPL activity. Furthermore, decreased plasma LPL activity was associated with elevated TG and low HDL-C levels in patient samples, which can contribute to CAD risk [34-37]. The HindIII polymorphism is located in intron 8, $495 \mathrm{bp}$ from the splice-donor site, and it can affect RNA splicing [38]. The H-allele of the HindIII polymorphism could cause either enhanced enzyme activity or more efficient lipid binding [34]. The Ser447X 
polymorphism is located in intron 9, where cytosine $(C)$ is replaced by guanine $(G)$, at position 1959. This polymorphism leads to the suppression of the final two amino acids, serine and glycine at position 447 of protein $[35,36]$. The PvuII polymorphism is located on intron $6,1.57 \mathrm{~kb}$ from the SA site. The region containing the PvuII site resembles the splicing site in its homology to the consensus sequence required for 39-splicing and the formation of the lariat structure, suggesting that C497-T change may interfere with the correct splicing of messenger RNA [17,37].

The association between the LPL polymorphism and CAD has been researched for thirty years. However, the results to date have been inconsistent. Currently, there are no large scale case control studies for LPL polymorphism and CAD risk. Thus, we performed a meta-analysis to study the association between LPL polymorphism and CAD risk. To analyze the association between the HindIII polymorphism and CAD risk, we reviewed seven studies including 1853 cases and 1171 controls that were conducted from 2000 to 2015. As shown in Figures 2 and 3, the analysis revealed that the HindIII $\mathrm{H}^{+} \mathrm{H}^{+}$genotype and the $\mathrm{H}^{+}$allele genotype were significantly associated with the risk of CAD. These results were consistent with previous reports that HindIII is the most common polymorphism of LPL associated with CAD risk. However, for the Ser447X polymorphism, the association with CAD was only found in the XX genotype; the other genotype had no significant association. The difference in the $X X$ genotype may have been caused by publication bias because two studies reported no events in the XX genotype $[15,25]$. More studies are needed to confirm this result. For the PvuII polymorphism, no significant association to CAD risk was detected.

However, there are some limitations in this study. First, based on our inclusion and exclusion criteria, the available studies that could be included in this meta-analysis were moderate. Thus, the results may be influenced by factors such as random error. Second, the results were based on individual unadjusted effect estimates, whereas a more precise evaluation would be adjusted by other potential risk factors, including age, sex, drinking status, cigarette consumption, etc. Third, the lack of individual-level data prevented further analyses to identify interactions between the genetic variations and the metabolic traits.

\section{Conclusions}

In conclusion, we found that the LPL polymorphisms HindIII $\mathrm{H}^{+} \mathrm{H}^{+}$genotype and $\mathrm{H}^{+}$allele genotype were significantly associated with the risk of CAD. The Ser447X XX genotype was also significantly associated with the risk of CAD. However, more studies are needed to confirm these findings. In contrast, the PvuII polymorphism had no association with the risk of CAD. We have concluded that LPL HindIII polymorphism might serve as a potential biomarker for CAD risk.

Author Contributions: Li Xie and You-Mei Li conceived this work and interpreted the data. You-Mei Li and $\mathrm{Li}$ Xie wrote the main manuscript and prepared all figures and tables. Both authors reviewed the manuscript.

Conflicts of Interest: The authors declare no competing financial interests.

\section{References}

1. Ardeshiri, M.; Faritus, Z.; Ojaghi-Haghighi, Z.; Bakhshandeh, H.; Kargar, F.; Aghili, R. Impact of metabolic syndrome on mortality and morbidity after coronary artery bypass grafting surgery. Res. Cardiovasc. Med. 2014, 3, e20270. [CrossRef] [PubMed]

2. Teo, K.K.; Cohen, E.; Buller, C.; Hassan, A.; Carere, R.; Cox, J.L.; Ly, H.; Fedak, P.W.; Chan, K.; Legare, J.F.; et al. Canadian Cardiovascular Society/Canadian Association of Interventional Cardiology/Canadian Society of Cardiac Surgery position statement on revascularization-multivessel coronary artery disease. Can. J. Cardiol. 2014, 30, 1482-1491. [CrossRef] [PubMed]

3. Ko, Y.L.; Hsu, L.A.; Hsu, K.H.; Ko, Y.H.; Lee, Y.S. The interactive effects of hepatic lipase gene promoter polymorphisms with sex and obesity on high-density-lipoprotein cholesterol levels in Taiwanese-Chinese. Atherosclerosis 2004, 172, 135-142. [CrossRef] [PubMed] 
4. Clee, S.M.; Kastelein, J.J.; van Dam, M.; Marcil, M.; Roomp, K.; Zwarts, K.Y.; Collins, J.A.; Roelants, R.; Tamasawa, N.; Stulc, T.; et al. Age and residual cholesterol efflux affect HDL cholesterol levels and coronary artery disease in ABCA1 heterozygotes. J. Clin. Investig. 2000, 106, 1263-1270. [CrossRef] [PubMed]

5. Bai, X.Y.; Li, S.; Wang, M.; Qu, X.; Hu, G.; Xu, Z.; Chen, M.; He, G.W.; Wu, H. Association of monocyte chemoattractant protein-1 (MCP-1)-2518A $>$ G polymorphism with susceptibility to coronary artery disease: A meta-analysis. Ann. Hum. Genet. 2015, 79, 173-187. [CrossRef] [PubMed]

6. Zhang, M.M.; Xie, X.; Ma, Y.T.; Zheng, Y.Y.; Yang, Y.N.; Li, X.M.; Fu, Z.Y.; Liu, F.; Chen, B.D. Association of COX-2-765G>C genetic polymorphism with coronary artery disease: A meta-analysis. Int. J. Clin. Exp. Med. 2015, 8, 7412-7418. [PubMed]

7. Kusunoki, M.; Tsutsumi, K.; Sato, D.; Nakamura, A.; Habu, S.; Mori, Y.; Morishita, M.; Yonemoto, T.; Miyata, T.; Nakaya, Y.; et al. Activation of lipoprotein lipase increases serum high density lipoprotein 2 cholesterol and enlarges high density lipoprotein 2 particles in rats. Eur. J. Pharmacol. 2011, 668, 337-339. [CrossRef] [PubMed]

8. Wang, Y.; Tong, J.; Li, S.; Zhang, R.; Chen, L.; Wang, Y.; Zheng, M.; Wang, M.; Liu, G.; Dai, Y.; et al. Over-expression of human lipoprotein lipase in mouse mammary glands leads to reduction of milk triglyceride and delayed growth of suckling pups. PLOS ONE 2011, 6, e20895. [CrossRef] [PubMed]

9. Voss, C.V.; Davies, B.S.; Tat, S.; Gin, P.; Fong, L.G.; Pelletier, C.; Mottler, C.D.; Bensadoun, A.; Beigneux, A.P.; Young, S.G. Mutations in lipoprotein lipase that block binding to the endothelial cell transporter GPIHBP1. Proc. Natl. Acad. Sci. USA 2011, 108, 7980-7984. [CrossRef] [PubMed]

10. Jensen, M.K.; Rimm, E.B.; Rader, D.; Schmidt, E.B.; Sorensen, T.I.; Vogel, U.; Overvad, K.; Mukamal, K.J. S447X variant of the lipoprotein lipase gene, lipids, and risk of coronary heart disease in 3 prospective cohort studies. Am. Heart J. 2009, 157, 384-390. [CrossRef] [PubMed]

11. Wion, K.L.; Kirchgessner, T.G.; Lusis, A.J.; Schotz, M.C.; Lawn, R.M. Human lipoprotein lipase complementary DNA sequence. Science 1987, 235, 1638-1641. [CrossRef] [PubMed]

12. Sayad, A.; Noruzinia, M.; Zamani, M.; Harirchian, M.H.; Kazemnejad, A. Lipoprotein Lipase HindIII Intronic Polymorphism in a Subset of Iranian Patients with Late-Onset Alzheimer's Disease. Cell J. 2012, 14, 67-72. [PubMed]

13. Tanguturi, P.R.; Pullareddy, B.; Rama Krishna, B.S.; Murthy, D.K. Lipoprotein lipase gene HindIII polymorphism and risk of myocardial infarction in South Indian population. Indian Heart J. 2013, 65, 653-657. [CrossRef] [PubMed]

14. Abu-Amero, K.K.; Wyngaard, C.A.; Al-Boudari, O.M.; Kambouris, M.; Dzimiri, N. Lack of association of lipoprotein lipase gene polymorphisms with coronary artery disease in the Saudi Arab population. Arch. Pathol. Lab. Med. 2003, 127, 597-600. [PubMed]

15. Al-Jafari, A.A.; Daoud, M.S.; Mobeirek, A.F.; Al Anazi, M.S. DNA polymorphisms of the lipoprotein lipase gene and their association with coronary artery disease in the Saudi population. Int. J. Mol. Sci. 2012, 13, 7559-7574. [CrossRef] [PubMed]

16. Georgiev, A.; Panov, S.; Sadikario, S. Association of PvuII polymorphism in the lipoprotein lipase gene with the coronary artery disease in Macedonian population. Prilozi 2008, 29, 213-225. [PubMed]

17. Duman, B.S.; Turkoglu, C.; Akpinar, B.; Guden, M.; Vertii, A.; Dak, E.; Cagatay, P.; Gunay, D.; Buyukdevrim, A.S. Lipoprotein lipase gene polymorphism and lipid profile in coronary artery disease. Arch. Pathol. Lab. Med. 2004, 128, 869-874. [PubMed]

18. DerSimonian, R.; Laird, N. Meta-analysis in clinical trials. Control. Clin. Trials 1986, 7, 177-188. [CrossRef]

19. Mantel, N.; Haenszel, W. Statistical aspects of the analysis of data from retrospective studies of disease. J. Natl. Cancer Inst. 1959, 22, 719-748. [PubMed]

20. Egger, M.; Davey Smith, G.; Schneider, M.; Minder, C. Bias in meta-analysis detected by a simple, graphical test. BMJ 1997, 315, 629-634. [CrossRef] [PubMed]

21. Begg, C.B.; Mazumdar, M. Operating characteristics of a rank correlation test for publication bias. Biometrics 1994, 50, 1088-1101. [CrossRef] [PubMed]

22. Ahmadi, Z.; Senemar, S.; Toosi, S.; Radmanesh, S. The association of lipoprotein lipase genes, HindIII and S447X polymorphisms with coronary artery disease in Shiraz city. J. Cardiovasc. Thorac. Res. 2015, 7, 63-67. [CrossRef] [PubMed] 
23. Almeida, K.A.; Strunz, C.M.; Maranhao, R.C.; Mansur, A.P. The S447X polymorphism of lipoprotein lipase: Effect on the incidence of premature coronary disease and on plasma lipids. Arq. Bras. Cardiol. 2007, 88, 297-303. [PubMed]

24. Aydogan, H.Y.; Isbir, S.; Kurnaz, O.; Gormus, U.; Isbir, T. Associations of lipoprotein lipase S447X and apolipoprotein E genotypes with low-density lipoprotein subfractions in Turkish patients with coronary artery disease. In Vivo 2009, 23, 155-161. [PubMed]

25. Daoud, M.S.; Ataya, F.S.; Fouad, D.; Alhazzani, A.; Shehata, A.I.; Al-Jafari, A.A. Associations of three lipoprotein lipase gene polymorphisms, lipid profiles and coronary artery disease. Biomed. Rep. 2013, 1, 573-582. [PubMed]

26. Ferencak, G.; Pasalic, D.; Grskovic, B.; Cheng, S.; Fijal, B.; Sesto, M.; Skodlar, J.; Rukavina, A.S. Lipoprotein lipase gene polymorphisms in Croatian patients with coronary artery disease. Clin. Chem. Lab. Med. 2003, 41, 541-546. [CrossRef] [PubMed]

27. Isbir, T.; Yilmaz, H.; Agachan, B.; Karaali, Z.E. Cholesterol ester transfer protein, apolipoprotein E and lipoprotein lipase genotypes in patients with coronary artery disease in the Turkish population. Clin. Genet. 2003, 64, 228-234. [CrossRef] [PubMed]

28. Pasalic, D.; Ferencak, G.; Grskovic, B.; Sesto, M.; Stavljenic-Rukavina, A. Association of two genetic variations of lipoprotein lipase, S447X and Hind III, with coronary artery disease and hypertriglyceridemia. Coll. Antropol. 2006, 30, 549-554. [PubMed]

29. Sawano, M.; Watanabe, Y.; Ohmura, H.; Shimada, K.; Daida, H.; Mokuno, H.; Yamaguchi, H. Potentially protective effects of the Ser447-Ter mutation of the lipoprotein lipase gene against the development of coronary artery disease in Japanese subjects via a beneficial lipid profile. Jpn. Circ. J. 2001, 65, 310-314. [CrossRef] [PubMed]

30. Whiting, B.M.; Anderson, J.L.; Muhlestein, J.B.; Horne, B.D.; Bair, T.L.; Pearson, R.R.; Carlquist, J.F.; Intermountain Heart Collaborative Study Group. Candidate gene susceptibility variants predict intermediate end points but not angiographic coronary artery disease. Am. Heart J. 2005, 150, 243-250. [CrossRef] [PubMed]

31. Corella, D.; Guillen, M.; Saiz, C.; Portoles, O.; Sabater, A.; Folch, J.; Ordovas, J.M. Associations of LPL and APOC3 gene polymorphisms on plasma lipids in a Mediterranean population: Interaction with tobacco smoking and the APOE locus. J. Lipid Res. 2002, 43, 416-427. [PubMed]

32. Socquard, E.; Durlach, A.; Clavel, C.; Nazeyrollas, P.; Durlach, V. Association of HindIII and PvuII genetic polymorphisms of lipoprotein lipase with lipid metabolism and macrovascular events in type 2 diabetic patients. Diabetes Metab. 2006, 32, 262-269. [CrossRef]

33. Nicklas, B.J.; Ferrell, R.E.; Rogus, E.M.; Berman, D.M.; Ryan, A.S.; Dennis, K.E.; Goldberg, A.P. Lipoprotein lipase gene variation is associated with adipose tissue lipoprotein lipase activity, and lipoprotein lipid and glucose concentrations in overweight postmenopausal women. Hum. Genet. 2000, 106, 420-424. [CrossRef] [PubMed]

34. Chen, Q.; Razzaghi, H.; Demirci, F.Y.; Kamboh, M.I. Functional significance of lipoprotein lipase HindIII polymorphism associated with the risk of coronary artery disease. Atherosclerosis 2008, 200, 102-108. [CrossRef] [PubMed]

35. Humphries, S.E.; Nicaud, V.; Margalef, J.; Tiret, L.; Talmud, P.J. Lipoprotein lipase gene variation is associated with a paternal history of premature coronary artery disease and fasting and postprandial plasma triglycerides: The European Atherosclerosis Research Study (EARS). Arterioscler. Thromb. Vasc. Biol. 1998, 18, 526-534. [CrossRef] [PubMed]

36. Ukkola, O.; Garenc, C.; Perusse, L.; Bergeron, J.; Despres, J.P.; Rao, D.C.; Bouchard, C. Genetic variation at the lipoprotein lipase locus and plasma lipoprotein and insulin levels in the Quebec Family Study. Atherosclerosis 2001, 158, 199-206. [CrossRef]

37. Oka, K.; Tkalcevic, G.T.; Stocks, J.; Galton, D.J.; Brown, W.V. Nucleotide sequence of PvuII polymorphic site at the human lipoprotein lipase gene locus. Nucleic Acids Res. 1989, 17, 6752. [CrossRef] [PubMed]

38. Murthy, V.; Julien, P.; Gagne, C. Molecular pathobiology of the human lipoprotein lipase gene. Pharmacol. Ther. 1996, 70, 101-135. [CrossRef]

(C) 2017 by the authors; licensee MDPI, Basel, Switzerland. This article is an open access article distributed under the terms and conditions of the Creative Commons Attribution (CC-BY) license (http://creativecommons.org/licenses/by/4.0/). 